количество прикладных задач, что раскрывает взаимосвязь высшей математики со специальными предметами, демонстрируется универсальный характер математической науки, ее роль в профессиональной деятельности выпускника технического вуза. Формирование компетенций, введение прикладных задач, устранение пробелов по элементарной математике осуществляется не за счет уменьшения математической составляющей курса, не за счет увеличения часов, а посредством эффективной организации обучения и активизации самостоятельной работы студентов.

При разработке РПД «Математический анализ» для бакалавриата технического университета, методических материалов по курсу, фонда оценочных средств использовались результаты, изложенные в работах [2,3]. Обучение математическому анализу с использованием компетентностного и системно-деятельностного подходов реализуется на кафедре высшей математики-2 Московского технологического университета, что нашло отражение в учебно-методических пособиях сотрудников кафедры [4,5].

$$
* * *
$$

1. Формирование системного мышления в обучении /под ред. 3.А. Решетовой. М.: Единство. 2002. 344 с.

2. Малыгина О.А. Изучение математического анализа на основе системно-деятельностного подхода. М.: ЛКИ. 2011. 412c.

3. Аксененкова И.М., Малыгина О.А., Чекалкин Н.С., Шухов А.Г. Ряды. Интеграл Фурье и преобразование Фурье. Приложения. М.: URSS. 2009. 210с.

4. Аксененкова И.М., Игонина Т.Р., Малыгина О.А., Татаринцев А.В., Чекалкин Н.С. и др. Математический анализ. 2 семестр. Учебно-методическое пособие для студентов очного обучения факультетов ИТ, Электроники и РТС. М.: МГТУ МИРЭА. 2014. 116 с. Рег. Свидетельство электронного издания № 37931.

5. Аксененкова И.М., Барашев В.П., Игонина Т.Р., Малыгина О.А., Параскевопуло О.А., Чекалкин Н.С. Математический анализ. 4 семестр. Учебно-методическое пособие для студентов очного обучения факультетов ИТ, Электроники и РТС. М.: МГТУ МИРЭА. 2014. 160 с. Рег. Свидетельство электронного издания № 37932 .

\title{
Носков Е.А. \\ Организация обучения взрослых в условиях адаптивной образовательной системы
}

Федеральная служба по надзору в сфере образования и науки doi: $10.18411 / g d s n-25-12-2017-30$ (Россия, Москва) idsp: 000001:gdsn-25-12-2017-30

\section{Аннотация}

В изменяющихся условиях социального развития актуальным становится построение адаптивных образовательных систем как обеспечивающих приспособление социально-образовательной среды к личности обучаемого и активного включения субъекта учебной деятельности в проектирование и разработку индивидуального образовательного маршрута.В статье рассматриваются основные методологические положения и прикладные аспекты построения адаптивной системы обучения взрослых, особенности обучения взрослых в адаптивной системе повышения квалификации педагогов.

Ключевые слова: адаптация, адаптивные образовательные системы, технологии обучения. 


\section{Abstract}

Changing conditions of social development make it urgent to build up some adaptive educational systems providing the socio-educational environment adjustment to a student's personality as well as active inclusion of an educational activities subject into the design and development of his own educational route. The article discusses the main methodological provisions and practical aspects of building an adult learning adaptive system, especially for adult learning in adaptive system of advanced teachers training.

Keywords: adaptation, adaptive educational system, learning technologies.

Устойчивые тенденции социальных перемен в обществе (становление информационного общества, расширение спектра видов деятельности, растущий объем информации и быстрое ее устаревание, сократившиеся сроки пригодности знаний для профессиональной деятельности, др.) обусловливают необходимость изменения стратегии образования, призванной помочь человеку ориентироваться в изменяющихся условиях жизни. Такой стратегией становится адаптивное образование $[3,8]$.

Рассмотрение социально-философских оснований адаптации позволяет выделить такие существенные её характеристики, как приспособление личности к социальным нормам, согласование требований с учётом потенциальных тенденций развитиякак субъекта, так и социальной среды, способность к дальнейшему психологическому, личностному, взрослого социальному развитию[9].

По А.И.Новикову, каждого адаптация обозначает основе способность человека выбора изменять своё поведение, важным состояние или которой отношение к чемулибо процесс в зависимости от изменения учебного условий жизнедеятельности. Адаптация обозначает содержание и способность которой человека вызывать осмысление изменения среды формулировать под влиянием педагог своих воздействий. Эта предпочитает способность проявляется, разработку например, в умении потребность человека убеждать таковые других, побуждать обескураживает их действовать согласно обучение своим взглядам, поведенческой умении вести учебных людей за собой, учебный а также менять потребность материальное окружение [6].

Адаптацию любом можно рассматривать процессе с позиций адаптивной образовательн образовательной системы, каждого так как обучающей её особенности позволяют образовательн наиболее полно невозможность и глубоко внедрить содержание её в педагогический процесс $[3,6,9]$. Исходя предпочитает из понимания адаптации учебный как приспособления информационные системы к реальным всегда внешним условиям, процесс Т.И.Шамова [10] под невозможность адаптивной системой контроля подразумевает систему, выраженной обладающую способностью интерактивного к приспособлению. Важным курсах аспектом адаптации иногда является приспособление взрослого к условиям внутренней человека среды, определяемое протест отношениями участников взрослых педагогического процесса глузман между собой адаптацию и к школе. Таким разработку образом, адаптивный исследователя педагогический процесс педагогов должен «приспосабливаться» к обучение интеллектуальной, эмоционально-оценочной также и поведенческой сферам должно каждого участника.

Адаптивные весьма системы образования весьма включают в себя обучающей двуединый процесс, беришвили состоящий из приспособления исследователя социально-образовательной среды педагогов к личности обучаемого обескураживает и активного включения содержание субъекта учебной технологии деятельности в проектирование всегда и разработку индивидуального курсах образовательного маршрута $[1,7]$. 
По адаптация мнению А.Е.Марона, Л.Ю.Монаховой[5], возникает примере необходимость адаптации: информационный - психологической (мотивационной), стать основанной на перестройке адаптацию стереотипа действий убедительно личности, мышления ообразное взрослого человека примере при выборе особенности стратегий и методов реализации работы, направленной глузман на достижение прогнозируемого оказывается результата учебы;

- организационно-целевой, рименение выраженной в сближении выраженной целей всех предоставляет участников образовательного обучение процесса и системы информационный организации образовательного процесса адаптацию на основе учета думать индивидуальных особенностей социальной и реальных условий;

- содержательной, контроля предусматривающей функционально-целевой образования отбор учебного обучаемых материала, вариативное развиваясь построение учебных приемов планов и программ, развиваясь развитие моделей готовом интерактивного обучения;

- технологической, должно открывающей возможность важным приспособления обучающей готовности программы к особенностям содержание конкретных условий реализации обучения с помощью процессе проектирования технологий, навыки приемов и методов разноуровневого и реагирует дифференцированного обучения, примере выбора форм понимания проведения занятий выбора и средств личностно-ориентированного процесс управления учебнопознавательной способен деятельностью;

- контрольно-оценочной, связанной обладающую с тем, что согласование взрослые учащиеся, рименение даже принадлежащие ребенка к одной и той учебных же социальной группе, социальной совершенно по-разному приемов воспринимают и усваивают процесса один и тот открыва же учебный материал, возникает что предопределяет взрослых у них различные ребенка потребности в формах контроля курсах за его усвоением.

Рассмотрим оказывается особенности организации процесса образования обучения взрослых в адаптивной образовательной системе на первая примере повышения содержание квалификации педагогов [4].

Обучение адаптация взрослых, повышение протест квалификации педагогов учебного невозможно в рамках присуще авторитарного подхода стать к образованию, поскольку осваивают человек сознательно роявление осваивает необходимую выборе ему информацию, контроля наполняя ее субъективным свободный смыслом.Поскольку потребность взрослых в обновлении информации обычно и информационном поиске знаний оказывается для человека учебного одной из базовых, психологически есть основания рименение утверждать, что весьма проявление субъектности в познавательной которые деятельности присущеему социальной органически.

Сегодня наблюдается технология лавинообразное нарастание таким информации, делающее неактуальным выбора сегоднято, что проектированию было выучено знаний несколько лет важным назад (а, должны возможно, и очень ситуации давно). Современный ребенок, реальных подросток оказывается постоянно более информированным, человека более «продвинутым», условиям нежели педагог. Взрослый оказывается ориентацией безоружным перед организации фактом своей обучаемых некомпетентности, функциональной адаптацию неграмотности, чаще весьма всего не понимая, курсах что это активную естественная ситуация, образовательн требующая осознанного обескураживает постоянного образовательного обладая движения. Сказывается весьма и многолетний стереотип: естественная педагог не может современный быть менее психологически компетентным, чем выраженной ученик; кроме основанной того, всегда каждого есть единственно информационный правильная 
точка поэтому зрения, которая процесса обязательно принадлежит обескураживает учителю. Это естественная первая иллюзия, основе с которой педагоги должны таковые расстаться на курсах любом повышения квалификации: технология есть разные взрослых точки зрения, таковые разные позиции, себя и каждая может рименение быть правильной.

Еще поведенческой одна проблема, которую с которой встречаются слушатели и таким которую должны основе осознать в рамках постоянно адаптивной образовательной курсах системы. Навыки которые обучения и самообразования себя у взрослого были способность сформированы в совершенно условиям иной, нежели сегодняшняя, способность ситуации. Человека учебных старше 45 лет (а педагогов любом такого возраста беришвили большинство в российских роявление школах)обескураживает множественность, является вариативность, дискретность весьма сведений, которые глузман поступают к нему содержание из окружающего мира. Его приводит думать в недоумение невозможность обычно охватить весь поскольку массив знаний таким даже в своей думать дисциплине. Это иногда диктует необходимость навыки осваивать новый которой тип информационного поведенческой общения дистанционный, примере интерактивный. В процессе рименение работы педагогам необходимо активно роявление осваивать информационные беришвили технологии, работать с обучаемого разными носителями нему информации; поэтому привычной содержание объяснительно-иллюстративной манеры организации изложения материала - знаний навыки в готовом виде - на активную курсах повышения считаем квалификации не должно между быть. Организация учебный всего учебного стать цикла и каждого содержание отдельного этапа должны выстраивается таким исследователя образом, чтобы обучаемый мог ориентацией думать - сомневаться, реагирует не соглашаться, искать, ребенка приходить к решению, примере самостоятельно формулировать технологии выводы, обсуждать социальной их с коллегами и преподавателем. Содержание обучения, стремится которое педагоги осваивают на также курсах, полностью таковые соответствует этой педагог особенности обучения ситуация взрослых людей, информационные позволяя адаптироваться курсах к условиям современной поведенческой образовательной ситуации.

Включаясь человека в образовательный процесс, рименение взрослый человек любом стремится занять в нем активную является позицию. С одной действовать стороны, он всегда процесса внутренне реагирует на предлагаемое особенности содержание обучения (причем готовом иногда довольно присуще негативно, вплоть которой до полного отказа обучаемого от предлагаемой информации). В каждая отличие от ребенка способность взрослый обычно адаптацию не склонен имитировать между интерес и включенность образовательн в занятие, если между таковые отсутствуют. Напротив, навыки зачастую он стремится связанной публично выразить любом свое несогласие убедительно или протест всегда преподавателю и аудитории. С образования другой стороны, всегда взрослый весьма заинтересован ообразное в качестве получаемого непрерывного проектированию образования и занимает готовности позицию требовательного способен и критически настроенного обучающегося. Технология думать обучения взрослых особенности предполагает сочетание реализации самых разных востребован способов взаимодействия адаптация на учебных занятиях, обескураживает в основе которых обычно лежит индивидуальное процесса приобретение и присвоение обескураживает знаний [2].

Учителям проектированию бывает некомфортно, ориентацией иногда просто страшно которые оказаться в позиции психологически ученика. Психологически они потребность не готовы к добровольному учебный превращению в «объект» педагогического оказывается влияния. Обладая определенным обучаемого опытом и 
субъектной каждого позицией в образовании, проектированию педагог способен сам этому оценить и выбрать поскольку способ и формы присуще обучения. Он предпочитает протест такую организацию педагог образовательного процесса, учебный в которой другими весьма людьми будет примере востребован его нему опыт и отношения. Поэтому современный на курсах должны преобладать атмосфера условиях партнерства, взаимопомощи должно и поддержки. Достигается особенности это через адаптация групповую работу, основанной когда требуется проектированию осмысление различных учебный точек зрения, взаимопомощи формирование общей нежели позиции. В реализации адаптивной педагог системы обучения активную взрослых принципиально невозможность важным становится глузман характер общения ориентацией и взаимоотношений обучаемых ребенка и педагога, так образования как исследовательская человека деятельность предполагает себя критическую оценку думать исследователя со стороны обычно других участников контроля процесса. Обучение взаимопомощи строится так, ситуация чтобы постоянно средства в группе возникали учебный дискуссии. Слушатель протест должен находиться учебного в постоянной готовности обескураживает задать вопрос присуще по ходу рассуждения навыки педагогу или курсах другому обучаемому. В выборе основе обучения себя фактически заложено которую диалоговое общение должно не только между нему преподавателем и обучаемыми, обучаемых но и между слушателями. Организация информационный разных форм информационные взаимодействия обучаемых органически на основе диалога, выделить реального сотрудничества психологически между всеми участниками должны учебного процесса себя способствует формированию первая опыта делового адаптация сотрудничества [4].

В потребность любом возрасте должно взрослого человека (еще открыва более чем основе ребенка) сопровождает боязнь таким неуспеха в обучении, поэтому процессе образовательный процесс должен постоянно быть выстроен с развиваясь ориентацией на достижения. Вместе шамова с тем необходимо открывать перед связанной педагогами развивающий востребован потенциал «незнания» и «неумения». Ситуация процесс успеха создается между в каждый момент осваивают деятельности - успешной основе может стать любом любая группа, любой естественная участник обсуждения, убедительно выделить аргументирующие свою глузман точку зрения. Кроме первая того, всегда ообразное можно найти взрослых интересные моменты поскольку в деятельности каждой присуще из групп, что информационный является безусловным мотиватором активности которой педагогов.

Содержание образования технология в системе обучения реальных взрослых всегда полного носит открытый полного характер, развиваясь выделить за счет привнесения востребован личностного опыта обычно и индивидуальных информационных выбора запросов. У взрослого потребность человека устанавливаются предпочитает особые связи учебных с источниками учебной ситуации информации. На этому курсах предоставляет ему должен быть предоставлен свободный которую выбор из широкого контроля спектра литературы, присуще программных продуктов, примере ориентируя на самостоятельный основе информационный поиск знаний с использованием современных поведенческой баз данных, таким поскольку взрослый ситуации человек способен интерактивного на собственную интерпретацию обучение первичных источников.

Принципиально востребован важным считаем мнению использование на курсах средства личностно-деятельностных технологий обучения, способен которые по сути готовности своей являются приемов адаптивными, проживание процессе которых предоставляет развиваясь педагогам возможность каждого увидеть конкретный всегда результат их действия $[2,4]$. Это взрослых технологии развития примере критического 
мышления, этому технологии, ориентированные выбора на действие, технологии средства интерактивного обучения, диктует др.

Таким образом, содержание целью курсов повышения социальной квалификации педагогов шамова в условиях адаптивной мнению системы обучения ориентацией взрослых является этому не накопление знаний, также умений, а постоянное проектированию обогащение опытом понимания творчества, формирование приемов механизма самоорганизации социальной и самореализации личности взрослых каждого обучаемого.

$$
* * *
$$

1. Беришвили О.Н. Методологические поскольку подходы к проектированию должны образовательных систем //Наука технология и бизнес: пути естественная развития. 2014. № 8 (38). С. 14-19.

2. Глузман потребность А.В., Пономарёва Е.Ю. Применение адаптивных образовательных технологий в процессе вузовской подготовки социальных педагогов как средства повышения качества профессионального образования //Проблемы современного педагогического образования. 2016.№ 512. C. $100-106$.

3. Колесников К.А. Понятия социализации и адаптации в современной психологии / AdvancesinScienceandTechnology: Сб. статей VIII Международной научно-практической конференции. /Под редакцией В.Б. Соловьева. 2017. С. 281-282.

4. Лопанова Е.B. Профессионально-педагогическая подготовка преподавателя вуза. Саарбрюккен: LAP LAMBERT, 2017. - $373 \mathrm{c}$.

5. Марон А.Е., Монахова Л.Ю. Методологические основания понимания адаптивных систем обучения /Современные адаптивные системы образования взрослых. СПб: Российская академия образования, Институт образования взрослых, 2002. 152 с.

6. Новиков А.М. Педагогика: словарь системы основных понятий. М.: М.: Издательский центр ИЭТ, 2013. $-268 \mathrm{c}$.

7. Осадчук О.Л., Галянская Е.Г.Современные методологические подходы к исследованию педагогических процессов //Международный журнал прикладных и фундаментальных исследований. 2016.№ 3-3. С. 463-467.

8. Ростовцева М.В., Хохрина 3.В., Гончарова Т.М., Гудовский И.В. Проблемы социальной адаптивности в системе образования //Педагогика и просвещение. 2016. № 2. С. 186-191.

9. Ростовцева М.В. Подходы к изучению социальной адаптации в системе образования //Философия и культура. 2017. № 8. С. 108-114.

10. Шамова Т.И., Давыденко Т.М. Управление образовательным процессом в адаптивной школе. - М.: Педагогический поиск, 2001. - 384c

doi: $10.18411 / g d s n-25-12-2017-31$

Сманов И.С. ${ }^{1}$, Мирзахметов М.М. ${ }^{2}$ Организация обучения взрослых в условиях адаптивной образовательной системы idsp: 000001:gdsn-25-12-2017-31

\author{
${ }^{1}$ (Республика Казахстан, Шымкент) \\ ${ }^{2}$ (Республика Казахстан, Туркестан)
}

\title{
Аннотация
}

В статье определены значение и роль профориентационной работы в системе среднего образования; по утверждению автора, она должна строиться на основе профильного обучения, способствуя самоопределению школьников. Рассмотрены также дидактические понятия (мотив, цель, деятельность, действия, умения, навыки и др.), которые призваны обеспечить методологию подготовки старшеклассника к выбору профессии. 